\begin{tabular}{|l|l|}
\hline $\begin{array}{l}\text { Arte y humanismo en el pensamiento de Adolfo Sánchez Vázquez. ¿Es posible una } \\
\text { teoría del arte a partir de los escritos de Karl Marx? }\end{array}$ & Titulo \\
\hline Durán Medraño, José María - Autor/a; & Autor(es) \\
\hline $\begin{array}{l}\text { De Raíz Diversa. Revista Especializada en Estudios Latinoamericanos (Vol. 2 no. 4 } \\
\text { jul-dic 2015) }\end{array}$ & En: \\
\hline México D.F. & Lugar \\
\hline $\begin{array}{l}\text { Programa de Posgrado en Estudios Latinoamericanos, Universidad Nacional } \\
\text { Autónoma de México }\end{array}$ & Editorial/Editor \\
\hline 2015 & Fecha \\
\hline & Colección \\
\hline Trabajo; Arte; Sánchez Vázquez, Adolfo; Marxismo; Estética; América Latina; & Temas \\
\hline Artículo & Tipo de documento \\
\hline $\begin{array}{l}\text { "http://biblioteca.clacsoedu.ar/Mexico/ppel-unam/20160627034936/Jose_Maria_Duran__Arte_y_humanismo_en_el_pensamiento_de_Add } \\
\text { olfo_Sanchez_Vazquez_Es_posible_una_teoria_del_arte_a_partir_de_los_escritos_de_Kar__Marx.pdf" }\end{array}$ & URL \\
\hline $\begin{array}{l}\text { Reconocimiento-No Comercial-Sin Derivadas CC BY-NC-ND } \\
\text { http://creativecommons.org/licenses/by-nc-nd/2.0/deed.es }\end{array}$ & Licencia \\
\hline
\end{tabular}

Segui buscando en la Red de Bibliotecas Virtuales de CLACSO http://biblioteca.clacso.edu.ar

Consejo Latinoamericano de Ciencias Sociales (CLACSO)

Conselho Latino-americano de Ciências Sociais (CLACSO)

Latin American Council of Social Sciences (CLACSO)

www.clacso.edu.ar

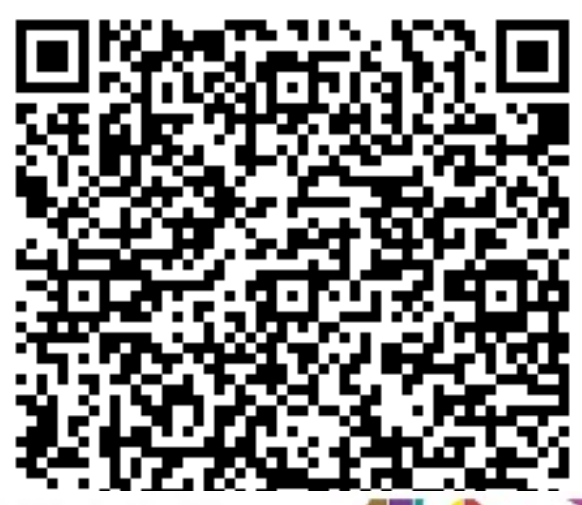

Consejo Latinoamericano de Ciencias Sociales

Conselho Latino-americano de Ciências Sociais 


\title{
Arte y humanismo en el pensamiento de Adolfo Sánchez Vázquez. ¿Es posible una teoría del arte a partir de los escritos de Karl Marx?
}

José María Durán MEdraño*

RESUMEN. El artículo presenta una lectura crítica de la teoría estética de Adolfo Sánchez Vázquez desde la perspectiva de una renovación necesaria de la estética y la teoría del arte marxistas. La pregunta clave que el artículo busca plantear es la siguiente: ¿es posible (re)construir una teoría del arte a partir de los escritos de Marx?; y si es así, ¿qué aspecto tendría esa teoría? Esta cuestión tiene en el punto de mira ciertas interpretaciones referidas al joven Marx y al Marx de El Capital, que Sánchez Vázquez aborda y cuya lectura es aquí rebatida.

Palabras Clave: Estética, marxismo, arte, trabajo, objetivación, enajenación.

\begin{abstract}
Aвstract: The article presents a critical reading of Adolfo Sánchez Vázquez' aesthetic theory from a perspective that considers the renewal of the Marxist aesthetics and art theory necessary. The key question that the author of the article poses is whether it is possible to (re)construct a theory of art from Marx's writings. If the answer is yes, how would such a theory look like? The investigation focuses on certain interpretations of the young Marx and the Marx from Capital that are also addressed by Sánchez Vázquez and the reading of which is discussed in this article.
\end{abstract}

KEYwORDS: Aesthetics, Marxism, art, work, objectification, alienation.

Recibido: 07 de enero de 2015. Aceptado: 29 de mayo de2015.

\section{PRESENTACiÓN}

$\mathrm{L}$ a estética juega para Adolfo Sánchez Vázquez ${ }^{1}$ un papel fundamental en la renovación del pensamiento de Marx y del marxismo en general. Este interés le sitúa en la línea del Marx humanista o de la interpretación humanista de Marx, como él mismo reconoce, con la cual comparte toda una serie de temas comunes cuya importancia para la estética ASV se encarga, una y otra vez, de subrayar. Temas que tienen que ver con la esencia

Profesor de Historia de la Cultura Europea en la Hochschule für Musik Hanns Eisler de Berlín.<jmduran@critical-aesthetics.com>

1 De ahora en adelante ASV. 
humana y la sensibilidad, o la contraposición entre trabajo creativo y enajenado. Tampoco es ninguna casualidad que el humanista sea un marxismo que reivindica la herencia hegeliana (Jay, 1984), lo cual tiene su relevancia como más adelante veremos. ASV abre su antología Estética y marxismo de 1970 - una de las más importantes en su género y, sin lugar a dudas, aún hoy insustituible - afirmando que su selección de textos no solo ha de contribuir a un conocimiento del estado de la estética marxista sino que también ha de "contribuir a borrar la imagen de ella como una estética cerrada, normativa y monolítica" (1970a: 16), lo cual es si cabe aún más importante considerando el pensamiento de ASV en su conjunto. ASV había comenzado sus estudios en el ámbito de la estética con una "concepción del arte como reflejo" (Conciencia y realidad en la obra de arte, su tesis de maestría de 1956) para pasar a rechazar muy pronto este modelo a partir de su encuentro con los conocidos como Manuscritos económico-filosóficos de 1844, los Manuscritos o Cuadernos de París, de Karl Marx. ${ }^{2}$ ASV escribe al respecto:

"Allí [en los Manuscritos de 1844] encontré un verdadero tesoro: no sólo una concepción del hombre, de la naturaleza y de la sociedad que no correspondía a la del Marx cientifista, objetivista, determinista que el marxismo oficial ofrecía, sino, a partir de las ideas estéticas que podían rastrearse en los Manuscritos, un pensamiento estético que echaba por tierra los principios de la llamada «estética marxista-leninista» (o estética soviética dominante)" (2007: 30).

La reivindicación del arte como trabajo creador no enajenado, que ASV comienza a desarrollar a partir de 1956, le lleva a formular una concepción plural del marxismo, la cual, por supuesto, no es ajena a los acontecimientos socio-políticos que agitan el marxismo en esa época, como el propio ASV explica muy bien (2007: 81-83). Esta concepción plural se refleja no sólo en su monumental Estética y marxismo (cf., por ejemplo, 1970b: 44), sino ya en su Filosofía de la praxis (1967/1980), la cual supone para ASV una ruptura con la metafísica materialista propia del Diamat (1995a: 234; 2003b: 521-522). Asimismo, en sus reflexiones acerca del socialismo y en

2 Un encuentro que rememora ese otro encuentro decisivo con los Manuscritos de 1844 como fue el de Lukács en 1930 en el Instituto Marx-Engels de Moscú (Lukács, 1970: 42). Sobre la importancia de su propio encuentro ver ASV, 1995a. 
su crítica al socialismo real también se puede observar muy bien esa forma antidogmática que tiene ASV de entender el marxismo. ${ }^{3}$

ASV afirma al comienzo de su estudio introductorio a Estética y marxismo que "[e]l primer problema que se plantea una estética marxista es esclarecer su propia relación con Marx, a fin de determinar el lugar que ocupan las cuestiones estéticas dentro de la doctrina que lleva su nombre" (1970b: 17). El intento comparte las inquietudes de una serie de pensadores marxistas que también han tratado de dilucidar lo que una estética en Marx podría ser o cuál sería el pensamiento estético de Marx - y también de Engels -. En cualquier caso, la cuestión no es nueva (cf. Daly, 2006). ${ }^{4}$ Aunque hay que dejar claro desde el inicio que esta es una cuestión bien diferente a la referida a la estética marxista per se, la cual - con un larga y rica tradición tras de sí, como la misma antología Estética y marxismo se encarga de mostrar de una manera magnífica -, como tal, puede adherirse al pensamiento estético de Marx o no - la concepción del realismo que tiene Lukács, por ejemplo, parte de un reivindicación directa de esta herencia, lo cual no deja de ser controvertido -. En lo que concierne al primer aspecto, esto es, el de una estética de o en Marx o, como lo apuntaba ASV más arriba, el de una estética que haga explícito "el lugar que ocupan las cuestiones estéticas" en la obra de Marx, queremos con este ensayo preguntarnos si es posible hablar de una estética o pensamiento estético en Marx, en cuanto que diferente a lo que sería abordar la estética marxista, asumiendo como básicamente correctas dos tesis que ASV postula en su estudio introductorio a Estética y marxismo:

“1a. Los juicios y observaciones de Marx y Engels no bastan para construir una estética marxista. $\mathrm{O}$, como hemos dicho en otro lugar: las ideas estéticas de Marx que se encuentran dispersas en sus obras no constituyen

3 Ver 2003a y 1999, y una visión de conjunto en 2007: 79-88.

4 Existen coincidencias importantes con autores tan relevantes como Lukács (1966), aunque ASV no deje de señalar sus diferencias con éste (cf. Durán Payán, 1995: 409), o Lifshitz (1981) - dos autores que de alguna manera preceden a ASV en lo que a la exposición de las ideas estéticas de Marx se refiere -; pero también con autores cuyas reflexiones son más o menos contemporáneas a las de ASV, como Fischer (1959/1967), Morawski (1973/2006), Prawer (1976), Marcuse (1977) o Rose (1984); por citar algunos de los nombres más conocidos a este respecto. Estamos convencidos de que un análisis que pusiera en relación todas estas formas diferentes, aunque relacionadas, de entender lo estético en el pensamiento de Marx, sería enormemente fructífero. Sea como fuere, tendremos que dejar este análisis para otra ocasión. 
"un cuerpo orgánico de doctrina, una estética de por sí”. 2a. En las tesis fundamentales de su teoría, (es decir, en su concepción del hombre, de la sociedad y de la historia) y no sólo en sus manifestaciones explícitas sobre arte y literatura están las bases de una estética que se articula de un modo necesario y esencial con esa concepción" (1970b: 19).

Si la primera de estas dos tesis la podemos considerar como un límite que es necesario reconocer cuando se quiere abordar el pensamiento estético de Marx; la segunda plantea cuestiones importantes relativas a la teoría de Marx y su método (cf. ibíd., 22-27), y cómo hemos de entender estos en relación a la estética en cuanto "disciplina específica que aporta razones para comprender el hecho artístico en su esencialidad” (ibíd., 26). En este artículo nos ocuparemos de problematizar esta segunda cuestión a través del análisis de un texto de ASV clave en este sentido: "Las ideas de Marx sobre la fuente y naturaleza de lo estético", publicado en 1965 en la primera parte del libro Las ideas estéticas de Marx (2005: 19-68). Este ensayo se trata de una reelaboración de otro publicado en 1961 con el revelador título de "Las ideas estéticas en los Manuscritos económico-filosóficos de Marx".

Nos gustaría ahora apuntar, siquiera brevemente, que la traducción inglesa de la versión de 1965 aparece ya en 1973, en donde ASV es presentado como representante destacado del pensamiento estético marxista antidogmático. Sólo podemos especular acerca del impacto que esta obra de ASV pudo haber tenido en generaciones de marxistas interesados en el pensamiento estético de Marx, y cuya principal fuente de información no podían ser los escritos originales en alemán, ni los debates que se dieron en el contexto alemán al respecto - por ejemplo, en relación al conocido como debate "Sickingen" (Hinderer, 1974) -, sino sólo traducciones al inglés. El importante libro de Lifshitz, La filosofía del arte de Karl Marx, cuya edición original en ruso data de 1933, ya había sido traducido al inglés en 1938, pero se reeditó en 1973. El estudio de Peter Demetz, Marx, Engels, and the Poets, es de 1967 (el original alemán es de 1959), siendo las conocidas antologías de Lang y Williams, Marxism \& Art. Writings in Aesthetics and Criticism, y la de Solomon, Marxism and Art. Essays Classic and Contemporary, de la misma época, 1972 y 1973 respectivamente, así como la antología de Baxandall y Morawski, centrada sólo en textos de Marx y Engels, que es de 1973. ${ }^{5}$ Finalmente, también en 1970 se publica de Lukács su "Marx and Engels on Aesthetics" (ver Lukács, 1945/1966).

5 El estudio introductorio de Morawski es de gran importancia (ver también Morawski, 1970). 
El siguiente testimonio de Bolívar Echeverría nos parece que ilustra muy bien la importancia del pensamiento de ASV, precisamente en esta época a caballo entre los años 1960 y comienzos de la década siguiente. Bolívar Echeverría recuerda cómo a comienzos de la década de 1960,

“[para] quienes estudiábamos en Alemania [...] era muy poco, por no decir nada, lo que, a parte de los ensayos de Mariátegui, los latinoamericanos podíamos presentar dentro de una línea teórica preocupada por reconstruir el discurso marxista. Por esta razón, recuerdo de manera muy especial la ocasión en que, excepcionalmente, pude presentar con orgullo el texto de un latinoamericano que podía resistir esas exigencias. Se trataba de un ensayo de Sánchez Vázquez sobre marxismo y estética que acababa de ser publicado en una revista de la Cuba entonces revolucionaria y en el que se esbozaba ya el intento posteriormente realizado de refundamentar el marxismo sobre la «teoría de la praxis»" (1995: 78-79).

Bolívar Echeverría se está refiriendo a esa primera versión de "Las ideas de Marx sobre la fuente y naturaleza de lo estético" que había sido publicada en la revista Dianoia de la unAm y reproducida poco después en Cuba.

Abordaremos el texto "Las ideas de Marx sobre la fuente y naturaleza de lo estético"6 sin pasar por alto las propias revisiones que ASV llevó a cabo de alguno de sus principales supuestos, sobre todo en lo que concierne al "concepto de esencia humana", cuyo "carácter especulativo" ASV se encarga de examinar críticamente en uno de los apéndices de Filosofía de la praxis (2003b: 482-498). Fundamental, en cualquier caso, es que la estética de ASV gira alrededor de una forma de entender el pensamiento de Marx que considera los Manuscritos de 1844 como un texto clave en este sentido. En Estética y marxismo ASV escribe:

"Las fuentes de la concepción social de lo estético se encuentran, sobre todo, en los Manuscritos económico-filosóficos de 1844, en donde el artecomo el trabajo - se presenta en relación con la necesidad del hombre de objetivar sus fuerzas esenciales, es decir, creadoras. Pero esta concepción puede apoyarse asimismo en los trabajos de madurez de Marx lo cual no puede sorprendernos si se tiene presente que dicha concepción es perfectamente congruente con la concepción del hombre que subyace en estos trabajos: el hombre como ser práctico, histórico y social, que al humanizar la naturaleza con su actividad práctica, crea un mundo de relaciones, valores y productos, del que forman parte la relación estética con la realidad, los valores estéticos y las obras de arte" (1970b: 31).

\footnotetext{
6 En lo sucesivo "Sobre la fuente y naturaleza de lo estético".
} 
Lo que de aquí se deriva, en cuanto que reflexión fundamental para una estética marxista fiel a Marx, es de gran importancia para un análisis del arte realmente existente, si se nos permite la expresión.

\section{LAS IDEAS FUNDAMENTALES DE LO ESTÉTICO EN MARX SEGÚN ASV}

Siguiendo el análisis realizado en Las ideas estéticas de Marx ASV resume las ideas fundamentales de lo estético en los siguientes ocho puntos (2007: 31-32, ver también 2005: 61):

1. el carácter histórico-social de la relación estética del hombre con la realidad y el arte;

2. la formación histórica de los sentidos propiamente estéticos: la vista y el oído;

3. el papel del trabajo, como transformación de la naturaleza o de la materia, en los orígenes del arte;

4. la positividad del trabajo en tanto expresión de la creatividad - negada en el trabajo enajenado - que se manifiesta en el arte, como trabajo creador;

5. el condicionamiento histórico-social e ideológico del arte y, no obstante ello, su autonomía o supervivencia respecto de ese condicionamiento;

6. la dialéctica de la producción y el consumo y, en términos estéticos, de la creación y la recepción;

7. la concepción del realismo como la forma de arte que, al representarla, da un conocimiento de la realidad; y

8. la idea de la hostilidad del capitalismo al arte al supeditarlo a las exigencias del mercado.

Abordaremos estos puntos en lo que sigue. No obstante, no vamos a tratar el punto 7 sobre el realismo porque, en primer lugar, es un debate que no nos interesa particularmente. En segundo lugar, se trata de un debate que tendría que plantear la posición de Lukács al respecto, que ASV somete a una dura critica (2005: 83-87 y 1970b: 28-29, 35). Abordar la estética y teoría del arte de Lukács excedería, sin embargo, los planteamientos iniciales de este artículo. Lo que sí nos gustaría apuntar ahora es que la posición de ASV con respecto al realismo sufre una drástica evolución, desde su apología del realismo como reflejo, anterior a 1956, hasta llegar a una concepción estética de la praxis (2007: 35), la cual pone el énfasis en el aspecto creador y activo del individuo social y, por ende, en una pluralidad de respuestas, concepciones 
o posiciones estéticas frente a la realidad (ibíd., 34). No deja de ser revelador que haya sido precisamente la reflexión estética la que le haya llevado a ASV a una concepción plural del marxismo. Esta concepción plural, frente a la objetividad gnoseológica pretendida por el realismo, tiene como su gran conclusión la dialéctica entre creación y recepción (punto 6), de la que ASV se ocupa en su última gran obra de estética, un conjunto de cinco conferencias que impartió a finales de 2004 en la Facultad de Filosofía y Letras de la unAm, y que fueron publicadas bajo el título De la estética de la Recepción a una estética de la participación. Por cuestiones de espacio tampoco vamos a poder abordar ahora este punto.

En relación al resto de los puntos, que habremos de tratar a continuación, apuntar que los puntos 1 a 4 se derivan de la lectura estética que ASV hace de los Manuscritos de 1844 de Marx, es decir, estos cuatro puntos se encontrarían, de alguna manera, formulados en los Manuscritos de 1844. Además, tanto el primer como el tercer punto pueden ser derivados del Marx de La ideología alemana y de las Tesis sobre Feuerbach, por lo que estarían en estrecha relación con la teoría de la praxis. Por otra parte, el punto 3 también encuentra cierto eco en el libro primero de El Capital. El punto 5 se puede poner en relación con el célebre pasaje acerca de los griegos en la importante introducción de 1857 en los Grundrisse, y el punto 8 aparece brevemente en los manuscritos económicos de 1861-63 que forman la base de Teorías sobre la plusvalía. No obstante, queremos subrayar de inicio que si bien todos estos puntos formulados por ASV se pueden poner en relación con pasajes bien conocidos de la obra de Marx, tanto de juventud como de madurez, ninguno de ellos se encuentra explícitamente formulado en Marx de la manera cómo ASV los expresa, lo que es sin duda problemático para la reconstrucción de una estética marxista que quiere tener la teoría y el método de Marx como su base.

Consideramos como auténticamente materialistas únicamente los puntos 1 y 6 . El punto 2 es materialista si tenemos en cuenta la formación histórica de todos los sentidos, y no únicamente de la vista y el oído. De hecho, considerar la vista y el oído como sentidos propiamente estéticos es Hegel, y no Marx, como más adelante veremos. En lo que respecta a los puntos restantes, aunque aparezcan formulados por Marx, ya veremos de qué manera, presentan una acusada base hegeliana e importantes coincidencias con Lukács - sobre todo, si pensamos en el Lukács de El joven Hegel y de la Ontología (ver Infranca, 2005) -. 


\section{LO ESTÉTICO EN LOS MANUSCRITOS DE 1844 DE MARX DE ACUERDO A LA LECTURA DE ASV EN “SOBRE LA FUENTE Y NATURALEZA DE LO ESTÉTICO”}

En "Sobre la fuente y naturaleza de lo estético" ASV analiza lo que considera como las ideas estéticas fundamentales de los Manuscritos de 1844. Éstas se conciben en directa confrontación con la estética idealista y materialista premarxista, en tanto que cuestionan lo estético 1) como propiedad o manifestación de la Idea (platónica o hegeliana), 2) como creación absoluta de la conciencia independientemente de la realidad material, y 3) como modo de ser de los objetos, o de sus cualidades formales (2005: 62). Para ASV lo que Marx viene a afirmar es que la relación estética "surge histórica, socialmente, sobre la base de la actividad práctica material" (ibíd., 63). Es decir, ASV lee la relación estética en el sentido de la filosofía de la praxis.

ASV sostiene que en los Manuscritos de 1844 Marx, buscando otra cosa, se topó con la "creación estética [...] como una dimensión esencial de lo que estaba buscando" (ibid., 19). Y lo que Marx estaba buscando era el hombre o, más bien, el ser social, es decir, el individuo sujeto a unas condiciones históricas y económicas concretas. Pero en estas condiciones sociales concretas con lo que Marx se encuentra es con un individuo deshumanizado; deshumanizado en las condiciones de la producción material, o sea, en el trabajo ${ }^{7}$ que ASV, siguiendo a Marx, considera como la esfera en la que el individuo debiera afirmarse como tal (2005: 19-20; Marx, 1993: 112-113).

Cuando Marx toma contacto con el proletariado urbano parisino alrededor de 1844 y comienza a estudiar economía política, el marco conceptual feuerbachiano sufre una transformación radical (Igea Laborda, 1981). Ahora en París, el proletariado ya no es más la personificación - más o menos idealizada - del sufrimiento humano, de la negación de la esencia humana, sino que aparece en su dimensión real, histórica (cf. Musto, 2011). ${ }^{8}$ Marx parte de una condición común al ser humano: la actividad práctica material, que Hegel ya había reconocido como enajenación, lo que Marx señala con aprobación, para a partir de ahí ir más allá de He-

\footnotetext{
7 Marx escribe en los Manuscritos de 1844: la realización (Verwirklichung) del trabajo se da como desrealización (Entwirklichung) del trabajador (1993: 106).

8 Por ello Althusser consideraba que la importancia decisiva de los Manuscritos de 1844 residía en que Marx introduce en una narrativa de inspiración feuerbachiana la historia como un proceso dialéctico, es decir, como un proceso de alienación del sujeto, haciendo de esta manera intervenir a Hegel en Feuerbach (2003: 248-249).
} 
gel al establecer la diferencia crucial entre enajenación (Entfremdung) y objetivación (Vergegenständlichung), o al remitir ésta a una determinada estructura de las relaciones sociales y de producción que es descrita con el término enajenación (Marx, 1993: 187-190). La enajenación, escribe ASV, es "una objetividad que se vuelve contra el sujeto" (2005: 27). Si con la enajenación la praxis productiva asume una realidad histórica concreta: la del trabajo enajenado, la objetivación se deduce como su opuesto, "negando idealmente [...] la realidad humana existente", escribe ASV en "El concepto de esencia humana en Marx" (2003b: 485). Es decir, de negar la enajenación "se obtiene la idea de un hombre que se define por su trabajo, pero por un trabajo creador en el que se afirma y reconoce a sí mismo" (ibíd.). Esta dialéctica de la objetivación, en cuanto exteriorización de las fuerzas esenciales del ser humano, y la enajenación, en cuanto condición histórica, concreta, de la objetivación, va a recorrer toda la estética de ASV. ASV asume esta dialéctica que lee en los Manuscritos de 1844 y que, según él, Marx mantiene en El Capital, por ejemplo, en el capítulo dedicado al fetichismo (1995a: 226).

No vamos a entrar ahora en una discusión acerca de la pertinencia de los conceptos de objetivación y enajenación usados por el joven Marx, y si estos aún mantienen su validez en sus obras de madurez. Más bien, nos centraremos a continuación en su significado para la reflexión estética, y, en consecuencia, nos preguntaremos a este respecto si una estética construida a partir de estos conceptos es una que podemos atribuir al propio Marx. Veamos, entonces, las tesis apuntadas por ASV más arriba.

\subsection{EXISTE UNA RELACIÓN PECULIAR ENTRE SUJETO Y OBJETO: LA RELACIÓN} ESTÉTICA. ESTA RELACIÓN SE DESARROLLA SOBRE UNA BASE HISTÓRICO-SOCIAL AUNQUE MANTIENE SU AUTONOMÍA CON RESPECTO A ÉSTA

ASV postula que el ser social sólo existe objetivándose, es decir, "creando objetos en los que se exterioriza" (2005: 27). La práctica estética surgiría de esta necesidad, que se realiza positivamente en el arte o la creación artística, pues "si lo estético pone de manifiesto al hombre como ser productor, transformador, la actividad artística tiene que fundarse en una praxis originaria de la que ella misma surge como una expresión superior" (ibíd., 20). ASV muestra cómo el arte nace a partir del trabajo (ibíd., 36 y ss.), postulando de una manera muy especulativa que el arte necesita para surgir de un determinado grado de productividad del trabajo que 
permita que los objetos se alejen de lo inmediatamente práctico-utilitario y puedan abrazar así cualidades estéticas (ibíd., 39-40). Así pues, ASV afirma que la relación estética no se reduce a una cualidad material, más propia de la relación práctico-utilitaria con el objeto, pero tampoco es enteramente subjetiva, pues "[n]o es una propiedad del sujeto, sino del objeto, y no de cualquier objeto, sino de un objeto subjetivizado, humanizado" (ibíd., 63). Una cosa es la objetividad del mármol, sostiene ASV, y otra la objetividad de la estatua como realidad estética, la cual está hecha de mármol. Si bien "[1]o estético abraza la condición física de la estatua" no se reduce a ella pues como realidad estética "no existe al margen del hombre social" (ibíd.): "El valor estético no es, por tanto, una propiedad o cualidad que los objetos tengan por sí mismos, sino algo que adquieren en la sociedad humana y gracias a la existencia social del hombre como ser creador" (ibíd., 67). Aquí establece ASV una analogía con la teoría del valor de Marx, pues el valor - ya hablemos del valor de uso o de cambio - no existe como una propiedad o cualidad de/en los objetos sino que es producto de la relación social (ibíd., 64-66).

En cualquier caso, si desde un punto de vista histórico-concreto la obra de arte, así como la relación estética, es el resultado de relaciones sociales determinadas, desde una perspectiva general-abstracta la obra de arte revela el proceso de "humanización de la naturaleza, de la materia, hasta sus últimas consecuencias” (ibíd., 38):

"La utilidad de la obra artística depende de su capacidad de satisfacer no una necesidad material determinada, sino la necesidad general que el hombre siente de humanizar todo cuanto toca, de afirmar su esencia y de reconocerse en el mundo objetivo creado por él" (ibíd.).

Y la esencia que el ser social necesita siempre afirmar es "su necesidad espiritual de objetivación" (ibíd.). ${ }^{9}$ ASV es así capaz de pasar del modo útil al estético, o sea, del trabajo al arte. Si en el trabajo los seres humanos crean objetos útiles en los que satisfacen sus necesidades, también expresan a través del trabajo sus fines, imaginación o voluntad, es decir, su esencia humana que se muestra, en cuanto tal, propiamente en la práctica

9 Esta necesidad espiritual no ha de ser confundida con el idealismo pues lo ideal, afirma ASV en respuesta a Ramón Xirau, conlleva como fin o proyecto la transformación de lo real, que a su vez parte de una prefiguración ideal de lo que aún no es (1995b: 366). A este respecto, sería sin duda de gran interés poner esta reflexión acerca de lo ideal en relación con el desarrollo que hace Ilyenkov del concepto (ver Ilyenkov 2014). 
artística. El discurso de la esencia se remite a lo expresado por Marx, en clave feuerbachiana, acerca del ser genérico que produce universalmente, es decir, liberado de la necesidad física. Por ello, el ser humano, concluye Marx, "crea también según las leyes de la belleza" (1993: 112).

ASV quiere, de esta manera, dar razón del hecho artístico en su universalidad, de la "praxis artística en su totalidad", más allá de las condiciones histórico-sociales en las que surge (1970b: 26); de ahí la tesis acerca de la autonomía de la creación artística con respecto a los condicionamientos histórico-sociales, que en la ponencia de 1972, "Socialización de la creación o muerte del arte", ASV expresa del siguiente modo: "El arte es [...], en todos los tiempos, independientemente del modo de apropiación dominante, un libro abierto en el que podemos leer hasta dónde se eleva la naturaleza creadora del hombre" (1996: 189). Así pues, el arte es constituido como necesidad humana esencial (2003b: 275-276). Esta necesidad de humanización que el arte hace realidad funciona, no obstante, como un horizonte ontológico que se ha de asumir de una manera axiomática.

Fijémonos en el papel crucial que juega la categoría de objetivación en este sentido (ASV, 2005: 24-28). Para ASV no hay duda de que la objetivación apunta a la necesidad humana de exteriorizar sus fuerzas esenciales en cuanto ser práctico, real, es decir, apunta a la creación de objetos en los que el ser humano se reconoce. El joven Marx lee esta estructura fundamental de la praxis humana, de la transformación de la realidad, en Hegel, ASV lo reafirma y comparte esta idea con Lukács, quien se había dado cuenta de la importancia crucial de esta categoría después de su encuentro con los Manuscritos de 1844 - lo que le llevará a analizarla en profundidad en su estudio del joven Hegel redactado en 1937 -. En los Manuscritos de 1844 Marx repite básicamente lo que Hegel ya había supuesto (Lukács, 1973: 505): "El producto del trabajo es el trabajo que se ha fijado en un objeto, que se ha hecho cosa; el producto es la objetivación del trabajo. La realización del trabajo es su objetivación" (Marx, 1993: 105). De ahí deduce Lukács el trabajo como "forma original" (Urform) de la praxis humana, como forma fundacional del ser humano, a la que apunta la categoría de objetivación: "una forma natural - ya sea positiva o negativa - del dominio del ser humano sobre el mundo" (1970: 42) y, por tanto, una forma que es "expresión de la vida social de los hombres" (ibíd., 26). Es evidente, continua Lukács, que estamos ante una forma "universalmente humana de las relaciones de los seres humanos entre sí” (ibíd.). ASV viene a decir 
lo mismo cuando afirma: "El hombre sólo lo es objetivándose, creando objetos en los que se exterioriza" (2005: 26-27). Esta exteriorización contiene la posibilidad del arte en cuanto producción que ha superado tanto la mera subsistencia como la relación práctico-utilitaria con los objetos. A la hora de describir la actividad práctico-material, ASV - como también Lukács (1973: 524 y ss.) - recurre a una concepción teleológica del trabajo, tanto utilitario como artístico. Este se muestra, al mismo tiempo, como origen y efecto del ser social.

En ASV encontramos un principio de causación: el trabajo, que se remite al hombre como causa de sí mismo. Kant ya había entendido de esta manera la finalidad natural de todo ser vivo autoorganizado, que es su causa y efecto al mismo tiempo, a diferencia de los artefactos cuya finalidad existe a priori en el espíritu de un diseñador inteligente (Thompson, 2011). Al entender al ser humano produciéndose a sí mismo a través del trabajo, ASV plantea el trabajo, o la praxis material, desde una perspectiva teleológica, es decir, como una actividad orientada a fines, y cuya razón de ser existe previamente en la conciencia del sujeto productor. El sujeto se realiza como tal sujeto en la praxis, es decir, objetivándose, y esta objetivación es el fruto de una transformación que se ha producido ya, idealmente, en la conciencia (ASV, 2005: 35). En el proceso de producción material la finalidad de los objetos "se da en la conciencia", siendo la finalidad "la expresión ideal de una determinada relación entre sujeto y objeto que encuentra su culminación en la transformación del segundo por el primero, es decir, en la práctica" (ASV, 1997: 178). A este respecto, ASV - como también Lukács (1973: 524) - se apoya en un conocido pasaje del capítulo quinto del libro primero de El Capital, en el que Marx había descrito el proceso de trabajo desde esta perspectiva teleológica (1986: 192-193; ASV, 1997: 178 y 2005: 35). En Filosofía de la praxis ASV mantiene esta concepción teleológica del trabajo en general, es decir, "como elemento determinante de la naturaleza humana en general” (2003b: 495). En referencia al pasaje mencionado de El Capital ASV escribe:

"El hombre queda definido así - esencialmente - por su trabajo, por su praxis productiva, o sea, por una actividad práctica con la que no sólo produce un mundo de objetos que satisfacen sus necesidades sino que se transforma y, por tanto, se produce a sí mismo" (ibíd.).

Pero el problema es que en ese pasaje Marx no está definiendo al hombre, sino el proceso de trabajo, cuya realidad - debemos reconocer - 
no puede ser reducida a la praxis material, en sentido estricto, sino que abarca complejas determinaciones que, como veremos a continuación, el concepto de objetivación deja sin considerar. Marx pone el énfasis en lo general, esto es, ha analizado, como él mismo dice, el proceso de trabajo en sus elementos simples y abstractos, como actividad orientada a fines, y ha dejado a un lado las relaciones sociales que determinan el proceso de trabajo (1986: 198). Después de esta breve descripción del trabajo en general, Marx vuelve al que era el objeto concreto de su interés: el capitalista (ibíd., 199). Que Marx describe aquí el proceso de trabajo de una forma abstracta y general es cierto, pero deducir de ahí que Marx ha definido el ser social en su esencia, es decir, en su trabajo, significa imponerle al texto de Marx un concepto, el del hombre y su esencia, que sencillamente no se encuentra en el texto.

El trabajo no es ni la esencia ni el origen del ser humano, y ello a pesar de que Marx nos diga en La ideología alemana que el ser humano comienza a diferenciarse de los animales en el momento en que empieza a producir sus medios de vida (1969: 21). Si ponemos esta definición del ser humano en relación con el pasaje mencionado del capítulo quinto de El Capital, simplemente apunta a una definición del trabajo en general, una definición de la que Marx nos dice en los Grundrisse que aunque útil no existe, es una abstracción (1983: 20). Es evidente que con lo que nos estamos enfrentando aquí es con el problema del origen del ser humano en el proceso de hominización (ver Engels, 1962 y Patterson, 2009) que Rousseau, en el Discurso sobre la desigualdad entre los hombres, se había negado a deducir a partir de una causa o principio. Según la historia que el sofista Protágoras nos cuenta - en el Protágoras de Platón -, no sería propiamente el conocimiento productivo, ${ }^{10}$ esto es, las téchnei que Prometeo roba de la forja de Hefesto, lo que hace a los seres humanos seres humanos, sino su sentido moral y de justicia que Zeus otorga a todos los seres humanos por igual, y que les permite convertirse en seres humanos políticos, v. gr. sociales (Platón, 1981: 524-527). Y es esta constitución social la cuestión realmente crucial en lo que respecta a los discursos que tratan de la esencia y los orígenes del ser humano; pues lo cierto es que al ser humano lo encontramos ya siempre inmerso en formaciones sociales concretas, cuyas estructuras no se reducen al hecho productivo, en sentido

10 Este conocimiento productivo es el que está en la base de la concepción teleológica del trabajo tanto en ASV como en Lukács. 
estricto, sino que engloban complejas relaciones políticas y de género. Así pues, cuando en El Capital Marx se refiere al trabajo, al trabajo útil que crea valores de uso, como una condición para la existencia de los seres humanos, como una necesidad natural (1986: 57), no deberíamos convertir esta condición general (Existenzbedingung) en la condición por excelencia que hace del ser humano humano (cf. Wolf, 2008: 61-63). Desde nuestro punto de vista, este es el error fundamental en el que cae ASV al tratar de explicar el ser humano a partir del concepto de objetivación. Además, se hace evidente que de acuerdo a su razonamiento, marcado por una concepción teleológica de la praxis, el ser humano es conciente de ser humano antes de poder serlo, es decir, el hombre que se objetiva en la praxis material, o sea, que se produce a sí mismo en el trabajo (2005: 25), es descrito como un ser humano consciente de su esencia antes de realizarse en la práctica material; y ello a pesar de que ASV insista en que lo fundamental de esta esencia es su dimensión práctica. Que el ser humano manifieste en la praxis material su necesidad de afirmarse o exteriorizarse como ser humano quiere simplemente decir esto: que el ser humano se reconoce en su esencia antes de realizarse como tal; lo cual es, cuando menos, extravagante (cf. Žižek, 2013: 261). De esta concepción esencialista del trabajo ASV deduce una, igualmente esencialista, referida a la creación artística, que ASV piensa que puede describir en su esencia independientemente de la forma social concreta que adopta y en la que surge.

En nuestra opinión, el ser humano que se objetiva en la producción material no existe previamente a ésta, sino que es ella. Esto es, no existe ninguna esencia que se va manifestando en la forma social concreta, sino que ésta, de existir, es la forma social concreta misma. Por ello, si queremos responder a la cuestión de lo que el arte es, no podemos buscar la respuesta en una estructura fundamental, o esencia, a partir de la cual todos los procesos concretos pueden ser lógicamente deducidos. Por el contrario, debería ser el proceso real histórico en el que el trabajo toma forma el auténtico objeto de estudio. Por esta razón, después de haber afirmado en los Manuscritos de 1844 que el ser humano crea según las leyes de la belleza, el Marx de La ideología alemana prefiere referirse al pintor Rafael condicionado por la organización social y la división del trabajo de su tiempo (1969: 377-378). El discurso acerca del ser genérico y su esencia ha desaparecido ahora por completo. Hemos de reconocer, empero, que ASV añade esta dimensión real-objetiva a su discurso de la esencia: que consiste en la tesis de la hostilidad del capitalismo al arte, que veremos un poco más adelante. 


\subsection{LOS SENTIDOS EN LA RELACIÓN ESTÉTICA}

ASV postula que tanto la relación práctico-utilitaria como la relación estética surgen cuando el ser humano ha superado el estadio de mera subsistencia:

"Para que un hombre pueda contemplar un objeto, juzgarlo, compararlo o transformarlo, se requiere que se haya liberado de la necesidad imperiosa; vital, que impide toda distancia entre sujeto y objeto. El hambriento sólo satisface su necesidad hundiéndose con el objeto, devorándolo; la contemplación - y la relación estética que tiene en ella su punto de partida - sólo es posible a partir de una separación sujeto-objeto en virtud del carácter específicamente humano de la necesidad que se satisface con él. El sujeto sólo puede contemplar, transformar y gozar humanamente del objeto en la medida que no se deja absorber o esclavizar por él” (2005: 50).

El aspecto crucial que debemos tener en cuenta ahora es la distancia o separación con el objeto, cuyo contrario supone la destrucción del objeto supuesta en la inmediata satisfacción de los apetitos en la relación natural. Sólo cuando el ser humano ha conseguido afirmarse frente a la naturaleza gracias al trabajo o la praxis material ${ }^{11}$ es posible la relación estética. Esta requiere que el objeto producto de la praxis material sea captado "sin una significación utilitaria directa" (ibíd., 51), o que el ser humano se afirme en él, "frente a la necesidad física inmediata o frente al estrecho utilitarismo", en toda su riqueza humana (ibíd., 53). Sólo así son las "cualidades de los objetos [...] percibidas como cualidades estéticas [...], o sea, como expresión de la esencia del hombre mismo" (ibíd., 51-52). Los sentidos humanos son fruto de este desarrollo pues su proceso de formación está inseparablemente unido al proceso de objetivación, es decir, al proceso de creación de objetos humanos (cf. Engels, 1962: 447). En este sentido, la distancia con el objeto es absolutamente necesaria para la relación estética, pues para poder situarse "en la actitud contemplativa que requiere la relación estética”, escribe ASV, el sujeto de dicha relación no puede verse

11 Que, en este sentido, ASV entiende de una forma plenamente hegeliana como una "satisfacción mediada" en la que la forma de la objetividad del objeto natural se destruye y recibe una nueva, lo que por su parte implica el extrañamiento (Entäußerung) del sujeto en una cosa que le es ajena (Lukács 1973: 505). Esta diferencia entre la satisfacción inmediata y la mediada gracias al trabajo es la que Hannah Arendt supo ver muy bien en La condición humana, donde se establece la distinción entre el homo faber que "trabaja con" y el animal laborans que "mezcla con" (1993: 157). 
limitado por la inmediatez de la relación natural (2005: 53). Si la superación de la inmediatez de la relación natural es para el ser humano el "fruto de un largo proceso histórico social [...] vinculado al creciente proceso de humanización de la naturaleza por el hombre" (ibíd., 52), también lo es la formación de los sentidos humanos que, como escribe Marx, "es un trabajo de toda la historia universal hasta nuestros días" (1993: 150). En el decurso de este proceso, escribe ASV, "el ojo y el oído se han convertido en sentidos estéticos" (2005: 55).

Estos sentidos "estéticos" son también los sentidos propiamente teóricos. En la historia de la filosofía han estado tradicionalmente asociados a las facultades cognitivas superiores: si los ojos han sido concebidos como el espejo del alma - vemos a través de los ojos, no con ellos, decía Platón -, el sonido está asociado a la palabra articulada entendida como la realidad concreta del pensamiento (ver Jonas, 1977). Dentro del discurso hegeliano los sentidos estéticos - vista y oído - funcionan en el modo de la "contemplación" (Anschauung), que presupone una distancia necesaria con el objeto percibido, es decir, presupone lo objetual, como algo ajeno a nosotros mismos (Hegel, 2006: 369). A fin, entonces, de poder contemplar la obra de arte como forma sensible, es necesario que ésta sea, primero, una realidad externa, para los sentidos, lo que sitúa el modo estético en absoluta correspondencia con el proceso de objetivación, del cual es parte. Mientras que la forma de percepción sensorial adecuada a la relación estética es la contemplación, Hegel excluye de ésta los sentidos prácticos, es decir, el olfato, el gusto y el tacto, porque en ellos la obra de arte deviene anulada, por ejemplo, "aquello que la lengua toca para degustarlo se disuelve en el acto" (ibíd.). Esta distinción entre el modo de contemplación estético-teórico y el modo práctico ha sido, por supuesto, crucial para todas las estéticas de inspiración formalista.

No deja de resultar extraño que ASV asuma acríticamente el ojo y el oído como sentidos propiamente estéticos. Siendo conscientes de la crítica de Marx al modo de contemplación en la primera tesis de las Tesis sobre Feuerbach, no parece muy coherente asumir la crítica de Marx al materialismo feuerbachiano por haberse quedado preso de la contemplación olvidándose de la práctica real (ASV, 2003b: 167-168), y - sin embargo - mantener la contemplación para el modo de percepción estético. La escueta referencia de Marx al oído musical y la belleza de la forma en los Manuscritos de 1844 (1993: 150) es, en este sentido, claramente insuficiente. Si queremos llegar 
a esa "estética de la participación" que ASV teoriza en sus últimos años, y en la que, como ya escribía en 1972, el arte supera el estado de objeto a ser contemplado para pasar a ser transformativo (1996: 198), tendremos, de alguna manera, que volver a reintegrar los sentidos prácticos en la relación estética y, así, poder dar cuenta de aquellas prácticas artísticas en las que la relación sujeto-objeto no es concebida en el sentido de la separación - supuesta en la objetivación -, sino que ésta supone mezclarse con los productos del trabajo incorporándolos, haciéndolos uno con nuestro cuerpo. Como escribía Walter Benjamin en La obra de arte en la época de su reproductibilidad técnica, no se trata de que las masas se sumerjan en la obra de arte, sino que sumerjan ésta en sí mismas (1973: 53).

Pensamos que es, en este sentido, que podemos volver al Marx de los Manuscritos de 1844 y su crítica al "sentido del tener" (1993: 148), que deberíamos poder reformular ahora como una crítica a la forma mercancía de los objetos cuya superación significa la creación de una sociedad de usuarios que satisface esa emancipación plena de los sentidos a la que Marx aspira.

3.3 LA TESIS DE LA HOSTILIDAD DEL CAPITALISMO AL ARTE: EL ARTE SE ENAJENA CUANDO SE SOMETE A LA LEY GENERAL DE LA PRODUCCIÓN MERCANTIL CAPITALISTA

En "Sobre la fuente y naturaleza de lo estético" ASV sostiene que Marx ya había señalado en los Manuscritos de 1844 lo que habrá de expresar de forma más clara en trabajos posteriores, a saber: "la contradicción entre arte y capitalismo, entre producción mercantil y libertad de creación" (2005: 60). A este respecto, no debemos olvidar lo que ASV expresa como el punto 4 de las ideas fundamentales de lo estético en Marx: la positividad del trabajo en tanto que expresión de la creatividad, es decir, de la objetivación como expresión de la praxis, que se manifiesta en el arte como trabajo creador frente al trabajo enajenado (cf. 2003b: 320-323). Ahora bien, ASV también reconoce que en los Manuscritos de 1844 Marx no se refiere explícitamente a una enajenación artística (2005: 60-61). En cualquier caso, para ASV la lógica del argumento que Marx expresa está fuera de toda duda. La enajenación de los sentidos bajo el "sentido del tener" (Sinn des Habens) en el régimen de propiedad privada afecta también a la relación estética, así: "El hombre necesitado, cargado de preocupaciones, no tiene sentido para el más bello espectáculo", escribe Marx (1993: 150). De igual manera, cuando la producción artística se somete al régimen de 
apropiación capitalista, a su mercantilización, su valor de uso estético se enajena: "Como «trabajo productivo", el trabajo artístico pierde lo que tiene de específico, de trabajo concreto y cualitativo superior, y sus productos se despojan asimismo de su naturaleza específica, cualitativa, para ser pura y simplemente mercancías" (ASV, 2005: 198; 1996: 190-192). En el trabajo enajenado, sostiene Marx, se invierte la relación medios-fines. La actividad práctica se convierte en un simple medio para el fin que es la existencia, cuando - sin embargo - la actividad práctica es el auténtico fin de la existencia del ser humano. "El trabajo enajenado -escribe Marx- invierte la relación, de manera que el hombre [...] hace de su actividad vital, de su esencia, un simple medio para su existencia" (1993: 112). Siguiendo la lógica de este argumento ASV escribe:

"Al convertir la obra de arte en mercancía, el fin en sí - necesidad interior de expresarse, de afirmar su esencia humana, social, al imprimir a una materia determinada forma - se convierte en medio de subsistencia y el artista deja de crear libremente, pues sólo puede crear así cuando despliega la riqueza de su ser frente a la necesidad exterior, satisfaciendo su necesidad interior como ser social" (2005: 60).

A este respecto, queremos señalar que postular la enajenación de la creación artística en el sistema de apropiación capitalista supone la necesidad de emprender un análisis de la producción artística desde el punto de vista de la crítica de la economía política, lo cual no está exento de problemas. Pues una de las cuestiones principales a la que nos enfrentamos en los $\mathrm{Ma}$ nuscritos de 1844 es que aquí Marx aún no había desarrollado las categorías fundamentales que luego operarán en El Capital; categorías tan importantes como la de fuerza de trabajo o la distinción entre trabajo concreto y abstracto (ver Nicolaus, 1972). La crítica de Marx en los Manuscritos de 1844 es, más bien, de naturaleza moral, es una crítica al egoísmo, al chanchulleo y la codicia. No son las relaciones de producción en cuanto tales el objeto de su análisis. Todo gira alrededor de la institución del mercado, que encarna todos los males de la sociedad burguesa. Ya sólo este aspecto sirve para poner en cuestión la tesis de la enajenación de la producción artística en el capitalismo sobre la base de los argumentos utilizados por Marx en los Manuscritos de 1844. En cualquier caso, no vamos a entrar ahora en un análisis pormenorizado de ello. Nos interesa, en cambio, confrontar la tesis de ASV con el Marx maduro, el de los manuscritos de la década de 1860. Pues la contradicción entre arte y capitalismo, entre producción mercantil y libertad de creación, que ASV expresa, nos conduce a la tesis principal 
de ASV en este sentido: la hostilidad del capitalismo al arte; y ésta es una frase literal del propio Marx. Veamos, primero, lo que Marx había escrito:

"Puesto que Storch no entiende la producción material desde una perspectiva histórica - la comprende sobre todo como producción de bienes, no como una forma específica históricamente desarrollada de esa producción - pierde pie, cuando sólo es sobre esta base que se puede comprender en parte el componente ideológico de la clase dominante, en parte la producción intelectual libre de esa formación social dada [...]. La relación no es para nada tan fácil como él piensa desde el comienzo. Por ejemplo, la producción capitalista es hostil a ciertas ramas de la producción intelectual, como por ejemplo la poesía y el arte. Acabaríamos por lo demás figurándonos lo que los franceses del siglo xvir, que Lessing había parodiado tan bien. Puesto que estamos en la mecánica etc. más avanzados que los antiguos, ¿porqué no podemos escribir también una epopeya? ¡Y la Henriada por la Ilíada!" (1977: 604; el subrayado es nuestro).

Para ASV el sentido de este pasaje es claro: "si la creación artística alcanza, en ciertos casos, determinado florecimiento no es gracias a la producción material capitalista sino a despecho de ella" (2005: 153). ASV cita este pasaje de Marx que discute, pero sólo aquello que le interesa resaltar, esto es, que "el capitalismo, por esencia es una formación económico-social ajena y opuesta al arte" (ibíd., 157). Es decir, ASV omite el contexto de la discusión de Marx en este ejemplo concreto. Esta omisión no es sólo achacable a ASV, Lukács y Lifschitz lo habían hecho igual antes que él.

¿Qué es, entonces, lo que Marx nos quiere contar a respecto de Henri Storch, y que concluye con esa aseveración tan rotunda de que el capitalismo es hostil a la poesía y el arte?

Storch se dirige contra Adam Smith pues éste habría cometido el error de excluir del trabajo productivo aquellos trabajos que no contribuyen $d i$ rectamente a la producción y la riqueza material. Quienes los ejercen no producen directamente riqueza material, sino que participan únicamente en su consumo. Storch está pensando aquí en la producción intelectual inmaterial, esto es, aquella que crea valores inmateriales inmediatos, y que está en estrecha relación con las facultades intelectuales y morales de la persona. Estos "bienes internos" (innere Güter) forman la base de la riqueza material, argumenta Storch, pues cuanto más civilizada sea una nación, más crece su riqueza nacional. Para Storch estos "bienes internos" pueden ser acumulados y, de hecho, contribuyen a la producción de riqueza, pero de una manera que les es propia. Es a través de su práctica y el correspondiente consumo que incrementan su valor. Así pues, la riqueza material 
no disminuye al ser consumida por éste trabajo inmaterial, sino que es en realidad un fantástico medio para incrementarla y, de esta manera, incrementar la propia civilización. Según Storch podríamos decir que el médico produce salud, y el poeta y el pintor gusto, y de esta manera contribuyen a la riqueza de la nación; lo cual no deja de ser una trivialidad pues, como ironiza Marx, de igual manera podríamos decir que la enfermedad produce médicos y la falta de gusto poetas.

Marx señala que a la hora de examinar las relaciones entre la producción material y la inmaterial o intelectual es primero necesario entender la producción material como una forma histórica determinada. Si no se entiende la determinación histórica del modo de producción es imposible entender la correlación entre la producción material y su correspondiente forma de producción intelectual y así, por ejemplo, entender porqué el capitalismo es hostil a ciertas forma de producción artística que no le corresponden como forma de producción. Lo que Marx postula aquí es simplemente que existen ciertas formas de arte y poesía que para el modo de producción capitalista aparecen ya superadas, de ahí su hostilidad; y no que el capitalismo sea intrínsecamente hostil al arte. Marx constata que al modo de producción capitalista le corresponden formas de producción intelectual diferentes a las del modo de producción feudal. En la afirmación de Marx resuena cierto eco de la tesis de la muerte del arte en Hegel, que se puede ver como un lamento por la pérdida del ideal clásico, aunque Hegel pensase que este ideal no podía retornar jamás porque las condiciones que lo habían visto nacer habían sido definitivamente superadas. Así pues, se pregunta Marx en ese famoso pasaje de la introducción de 1857 en los Grundrisse: ¿Es realmente posible la Ilíada con la prensa y la máquina de imprimir? (1983: 45). La misma imposibilidad, o posibilidad, del poema épico bajo relaciones de producción cambiantes es el resultado del proceso sociohistórico, y en éste radica la complejidad del análisis (cf. Schröder, 1986).

\section{CONCLUSIÓN}

Sin duda, una de las grandes aportaciones de ASV a la estética ha sido su insistencia en fundamentar la relación estética en la relación social, es decir, en considerar que el arte no puede analizarse al margen de las distintas relaciones sociales "con las que se encuentra en una relación de dependencia e influencia mutuas" (1970b: 24). El arte es "parte de una 
relación social determinada [...], se halla en una relación histórica", "está hecho de historia y él mismo es historia [...], el arte no escapa nunca de la historia ya que es la praxis de un ser histórico", escribe ASV (ibíd., 25). Al considerar el arte desde la perspectiva de la praxis del ser social ASV busca superar las limitaciones propias del materialismo contemplativo (Feuerbach) así como del idealismo (Hegel). Ahora bien, ¿extrae ASV las conclusiones correctas que se corresponden con este punto de partida? En nuestra opinión, el concepto de objetivación impide, precisamente, un análisis del arte como parte de la relación social.

La praxis, o actividad transformadora del sujeto, es examinada por ASV en el sentido de una estructura o sustancia fundamental que caracteriza a todos los seres humanos por igual, independientemente de las condiciones históricas concretas, es decir, se le confiere a esta sustancia una realidad que pre-existe el despliegue real-concreto del individuo en la historia. La actividad concreta de los individuos significa, en este sentido, el paso - necesario - de la potencia al acto. A partir de aquí ASV deduce la práctica artística como modo superior de la praxis (ibíd., 43), en el sentido de que se desarrolla a partir de ella, pero "como proceso de renovación e innovación constante que no puede agotarse nunca en ninguna de sus manifestaciones históricas concretas" (ibíd., 24).

ASV entiende el proceso histórico determinado por la dialéctica de la objetivación - esto es, la sustancia del ser social - y la enajenación - o la realidad concreta en la que ésta se encuentra -. En Filosofía de la praxis ASV escribe: "la historia humana no es sino la historia de la enajenación del ser humano en el trabajo" (2003b: 146). En los términos de la relación estética ASV reinterpreta esta dialéctica de la objetivación y la enajenación como la contradicción entre la creación auténtica y la hostilidad del capitalismo al arte. Esta dialéctica parte de una concepción del hombre y el trabajo que ASV lee en todos los escritos del Marx joven y maduro. Es al poner de manifiesto la explotación del productor en la sociedad capitalista que Marx, nos dice ASV, revela la contradicción entre capitalismo y creación (1970b: 21-22). Esta contradicción recorre por entero la reflexión estética de ASV, esto es, la condiciona por completo. En este sentido, lo que se presenta como el análisis del proceso histórico concreto, se despliega no en cuanto realidad concreta, con sus determinaciones específicas, sino como una dialéctica entre conceptos que han sido establecidos de antemano. La realidad se encuentra ya explícita en los 
conceptos, que únicamente se han de aplicar a lo concreto para, así, poder ver la realidad revelarse en su esencia. De esta manera, los conceptos se imponen a las prácticas realmente existentes, dotándolas de un sentido que se ha construido previo al examen de las prácticas mismas.

A este respecto, nos debemos preguntar si esta dialéctica entre conceptos preestablecidos se encuentra, de esta manera, en los escritos de Marx, o si se trata, más bien, de un objeto extraño que se le impone a los textos. Pues lo que para ASV es evidente, a saber: que la teoría de la enajenación del trabajo en el capitalismo (el Marx joven) continua en El Capital con el análisis del proceso de explotación como proceso de producción de plusvalía (ibíd., 22), no lo es tanto si examinamos que el sujeto del trabajo enajenado ha desaparecido por completo en el Marx maduro, pues el hombre enajenado en su esencia de los Manuscritos de 1844 se ha transformado en El Capital en fuerza de trabajo abstracta. Esto quiere simplemente decir que es ciertamente problemático asumir una continuidad entre la obra del Marx joven y el Marx maduro sin tener en cuenta las importantes diferencias que existen entre los textos, y lo que éstas significan para el análisis que queremos emprender. Desde nuestro punto de vista, un análisis de las relaciones concretas entre capitalismo y práctica artística que haga uso del instrumentario que Marx puso a disposición nos ha de llevar a una crítica de la economía política del arte (Durán Medraño, 2014), y no a una estética o teoría del arte en Marx, que no se encuentra por ningún lado. Esta es una crítica que ha de decidir, radicalmente, de dónde extrae sus conceptos: o bien de la teoría de la enajenación (el Marx joven), o bien de $E l$ Capital y sus manuscritos adyacentes (el Marx maduro). Si escogemos esta segunda opción, habremos de reconocer - si queremos ser fieles al texto de Marx - que son las relaciones de producción concretas el objeto real del análisis; y estas pueden mostrar tanto contradicciones específicas y dialécticas de liberación entre capitalismo y arte, como una total aquiescencia entre ambos. En cualquier caso, este análisis de las condiciones y determinantes socio-económicos concretos de la práctica artística no lo realiza Marx; por lo que ésta es una práctica teórica que aún ha de ser desarrollada.

Es cierto que en el análisis de ASV acerca de la praxis estética el énfasis en el sujeto de la praxis que se produce a sí mismo tiene como su objetivo principal desmontar las falacias del determinismo mecanicista marxista que veía la praxis del individuo únicamente como reflejo de las contradicciones objetivas; un análisis que en la reflexión estética se traducía en un puro sociologismo e ideologismo (ASV, 1970b: 18). Pero este objetivo, que 
busca para el ser social la reapropiación de su ser práctico, usurpada en la ideología del marxismo vulgar y el Diamat, por loable que nos parezca, no podemos permitir que se imponga al análisis de lo concreto cegándonos, de esta manera, frente a las determinaciones realmente existentes.

\section{BiBLIOGRAFÍA}

ALTHUSSER, L. (2003 [1967]); "The Humanist Controversy", The Humanist Controversy and Other Writings. Londres: Verso, pp. 221-305.

ARENDT, H. (1993); La condición humana, traducción de Ramón Gil. Barcelona: Paidós.

BENJAMIN, W. (1973); "La obra de arte en la época de su reproductibilidad técnica”, Discursos interrumpidos, I, edición de Jesús Aguirre. Madrid: Taurus, pp. 15-57.

ECHEVERRÍA ANDRADE, B. (1995); "Elogio del marxismo", en G. Vargas Lozano (ed.), En torno a la obra de Adolfo Sánchez Vázquez (filosofía, ética, estética y política). México D.F.: UNAM, pp. 77-82.

DALY, M. (2006); "A Short History of Marxist Aesthetics", en L. Baxandall y S. Morawski (eds.), Karl Marx \& Frederick Engels on Literature and Art. Nottingham: CCCP, pp. i-xxvi.

DURÁN MEDRAÑO, J. M. (2014); "A vueltas con la categoría de valor en la producción de arte", en Eptic Online, 16, 3 (Septiembre-Diciembre), pp. 136-149.

DURÁN PAYÁN, S. (1995); “Sánchez Vázquez: su aportación a la estética”, en G. Vargas Lozano (ed.), En torno a la obra de Adolfo Sánchez Vázquez (filosofía, ética, estética y política). México D.F.: UNAM, pp. 407-416.

ENGELS, F. (1962); “Anteil der Arbeit an der Menschwerdung des Affen”, Dialektik der Natur. Berlín: Dietz Verlag, pp. 444-455.

FISCHER, E. (1959); Von der Notwendigkeit der Kunst. Dresden: Verlag der Kunst - (1967); La necesidad del arte. Barcelona: Península.

HEGEL, G. W. F. (2006); Filosofía del arte o Estética (verano de 1826), edición de A. Gethmann-Siefert y B. Collenberg-Plotnikov. Madrid: Abada Editores.

HINDERER, W., ed. (1974); Sickingen-Debatte. Neuwied: Luchterhand.

IGEA LABORDA, A. (1981); "Las influencias de Hegel y Feuerbach en la primera obra teórica de Marx", en Revista de Estudios Políticos, 22 (Julio-Agosto), pp. 185-212.

ILYENKOV, E. (2014); "Dialectics of the Ideal", en A. Levant y V. Oittinen (eds.), Dialectics of the Ideal. Evald Ilyenkov and Creative Soviet Marxism. Chicago: Haymarket Books, pp. 25-78. 
INFRANCA, A. (2005); Trabajo, individuo, historia. El concepto de trabajo en Lukács. Buenos Aires: Herramienta.

JAY, M. (1984); Marxism \& Totality. The Adventures of a Concept from Lukács to Habermas. Berkeley: University of California Press.

JONAS, H. (1977); “Der Adel des Sehens. Eine Untersuchung zur Phänomenologie der Sinne", Das Prinzip Leben. Frankfurt am Main: Suhrkamp, pp. 233-264.

LIFSHITZ, M. (1981 [1933]); La filosofía del arte de Karl Marx. México D.F.: Ediciones Era.

LUKÁCS, G. (1966 [1945]); “Introducción a los escritos estéticos de Marx y Enge1s”, en Aportaciones a la historia de la estética, edición de Manuel Sacristán. México D.F.: Grijalbo, pp. 231-260.

LUKÁCS, G. (1970); Geschichte und Klassenbewußtsein. Neuwied: Luchterhand. , (1973); Der junge Hegel, Band 2. Frankfurt am Main: Suhrkamp.

MARCUSE, H. (1977); Die Permanenz der Kunst - Wieder eine bestimmte marxistische Ästhetik. Múnich: Carl Hanser.

MARX, K. (1977); Zur Kritik der politischen Ökonomie (Manuskript 1861-1863), MEGA II/3.2. Berlín: Dietz Verlag.

, (1983); Ökonomische Manuskripte 1857/1858, Band 42. Berlín: Dietz Verlag.

, (1986); Das Kapital, erster Band. Berlín: Dietz Verlag.

(1993); Manuscritos. Economía y filosofía, edición de Francisco Rubio Llorente. Madrid: Alianza Editorial.

, ENGELS, F. (1969); Die deutsche Ideologie. Berlín: Dietz Verlag.

MORAWSKI, S. (1970); “The Aesthetic Views of Marx and Engels”, en The Journal of Aesthetics and Art Criticism, 28, 3 (primavera), pp. 301-314.

, (2006 [1973]); "Introduction", en L. Baxandall y S. Morawski (eds.), Karl Marx \& Frederick Engels on Literature and Art. Nottingham: CCCP, pp. 1-40.

MUSTO, M. (2011); "Marx en París: los Manuscritos económico-filosóficos de 1844", en M. Musto (coord.), Tras las huellas de un fantasma, La actualidad de Karl Marx. México D.F.: Siglo XXI, pp. 116-132.

NICOLAUS, M. (1972); El Marx desconocido. Barcelona: Anagrama.

PATTERSON, T. (2009); Karl Marx, Anthropologist. Oxford y Nueva York: Berg.

PLATÓN (1981); Protágoras, traducción de Carlos García Gual. Madrid: Gredos.

PRAWER, S. S. (1976); Karl Marx and World Literature. Oxford: Oxford University Press.

ROSE, M. A. (1984); Marx's lost aesthetics. Karl Marx \& the visual arts. Cambridge: Cambridge University Press. 
SÁNCHEZ VÁZQUEZ, A. (1970a); “Prólogo”, en A. Sánchez Vázquez (Comp.), Estética y marxismo, Tomo I. México D.F.: Ediciones Era, pp. 11-16.

, (1970b); "Introducción general. Los problemas de la estética marxista”, en A. Sánchez Vázquez (Comp.), Estética y marxismo, Tomo I. México D.F.: Ediciones Era, pp. 17-73.

, (1973); Art and Society. Essays in Marxist Aesthetics. Nueva York: Monthly Review Press.

, (1995a); "Los Manuscritos de 1844 de Marx en mi vida y en mi obra", en G. Vargas Lozano (ed.), En torno a la obra de Adolfo Sánchez Vázquez (filosofía, ética, estética y política). México D.F.: UNAM, pp. 221-236.

, (1995b); "A Xirau: hacer real una sociedad ideal”, en G. Vargas Lozano (ed.), En torno a la obra de Adolfo Sánchez Vázquez (filosofía, ética, estética y política). México D.F.: UNAM, pp. 365-366.

, (1996 [1972]); "Socialización de la creación o muerte del arte", Cuestiones estéticas y artísticas contemporáneas. México D.F.: FCE, pp. 187-203.

, (1997 [1961]); “Contribución a una dialéctica de la finalidad y la causalidad”, Filosofía y circunstancias. Barcelona/México D.F.: Anthropos/ UNAM, pp. 169-188.

, (1999 [1981]); "Ideal socialista y socialismo real", Entre la realidad y la utopía. Ensayos sobre política, moral y socialismo. México D.F.: FCE/ UNAM, pp. 165-182.

, (2003a [1970/71]); "Del socialismo científico al socialismo utópico", El valor del socialismo. Madrid: El Viejo Topo, pp. 29-85.

, (2003b); Filosofía de la praxis. México D.F.: Siglo XXI.

, (2005 [1965]); Las ideas estéticas de Marx. México D.F.: Siglo XXI.

, (2007); Creación, estética y filosofía política. Mi recorrido intelectual. Madrid: Editorial Complutense.

SCHRÖDER, W. (1986); "Die Entfaltung des industriellen Kapitalismus und der Epochenwechsel im ästhetischen Denken”, en Marx-Engels-Jahrbuch, Bd. 9. Berlín: Dietz Verlag, pp. 163-221.

THOMPSON, E. (2011); "Lebewesen als Naturzwecke und autopoietische Systeme”, en T. Schlicht (ed.), Zweck und Natur. Historische und systematische Untersuchungen zur Teleologie. Múnich: Wilhelm Fink, pp. 167-193.

WOLF, F. O. (2008); "Kein zeit- und lebloses Denken - eine Kritik an Georg Lukács' Ontologie der Arbeit”, en G. Peter y F. O. Wolf, Welt ist Arbeit. Münster: Westfälisches Dampfboot, pp. 55-64.

ŽIŽEK, S. (2013); Less Than Nothing. Hegel and the Shadow of Dialectical Materialism. Londres: Verso. 